\title{
Provisional Life Expectancy Estimates for 2020
}

\author{
Elizabeth Arias, Ph.D., Betzaida Tejada-Vera, M.S., Farida Ahmad, M.P.H., and \\ Kenneth D. Kochanek, M.A.
}

\section{Introduction}

The National Center for Health Statistics (NCHS) collects and disseminates the nation's official vital statistics through the National Vital Statistics System (NVSS). NCHS uses provisional vital statistics data for conducting public health surveillance and final data for producing annual national natality and mortality statistics. NCHS publishes annual and decennial national life tables based on final vital statistics. To assess the effects on life expectancy of excess mortality observed during 2020, NCHS published provisional life expectancy estimates for the months January through June, 2020 in February 2021 (1). This report presents updated estimates of life expectancy based on provisional mortality data for the full year, January through December, 2020. Provisional data are early estimates based on death certificates received, processed, and coded, but not finalized, by NCHS. These estimates are considered provisional because death certificate information may later be revised, and additional death certificates may be received until approximately 6 months after the end of the year.

This report presents life expectancy estimates calculated using abridged period life tables based on provisional death counts for 2020, by sex, for the total, Hispanic, non-Hispanic white, and non-Hispanic black populations. Estimates for the American Indian and Alaska Native (AIAN), Asian, and Native Hawaiian and Other Pacific Islander (NHOPI) populations were not produced due to the impact of race and ethnicity misclassification on death certificates for these populations on the precision of life expectancy estimates (2). There are two types of life tables: the cohort (or generation) and the period (or current) life table. The cohort life table presents the mortality experience of a particular birth cohort from the moment of birth through consecutive ages in successive calendar years. The period life table does not represent the mortality experience of an actual birth cohort but rather presents what would happen to a hypothetical cohort if it experienced throughout its entire life the mortality conditions of a particular period. Period life expectancy estimates based on final data for 2019 by sex, Hispanic origin, and race are also provided in this report for purposes of comparison (see Technical Notes and reference 3 for description of methodology). Unlike the previous estimates based on 6 months of data, this full-year report presents contributions of causes of death to the changes in life expectancy using a life table partitioning technique (see Technical Notes).

Keywords: life expectancy $\bullet$ Hispanic origin $\cdot$ race $\cdot$ cause of death $\bullet$ National Vital Statistics System

\section{Data and Methods}

Provisional life expectancy estimates were calculated using abridged period life tables based on provisional death counts for 2020 from death records received and processed by NCHS as of May 13, 2021; provisional numbers of births for the same period based on birth records received and processed by NCHS as of April 7, 2021; and, July 1,2020 , monthly postcensal population estimates based on the 2010 decennial census. Provisional mortality rates are typically computed using death data after a 3-month lag following date of death, as completeness and timeliness of provisional death data can vary by many factors, including cause of death, month of the year, and age of the decedent $(4,5)$. Mortality data used in this report include over $99 \%$ of the deaths that occurred in 2020, but certain jurisdictions and age groups may be underrepresented for later months (5). Deaths requiring investigation, including infant deaths, deaths from external injuries, and drug overdose deaths may be underestimated $(6,7)$. See Technical Notes for more information about the calculation of the abridged period life tables, 2019 life expectancy estimates by race and Hispanic origin, and life table partitioning by cause of death.

\section{Results}

\section{Life expectancy in the United States}

The Table summarizes life expectancy by age, Hispanic origin, race, and sex. Life expectancy at birth represents the average number of years a group of infants would live if they were to experience throughout life the agespecific death rates prevailing during a specified period. In 2020, life expectancy at birth for the total U.S. population 
Table. Provisional expectation of life, by age, Hispanic origin, race for the non-Hispanic population, and sex: United States, 2020

\begin{tabular}{|c|c|c|c|c|c|c|c|c|c|c|c|c|}
\hline \multirow[b]{2}{*}{ Age (years) } & \multicolumn{3}{|c|}{ All races and origins } & \multicolumn{3}{|c|}{ Hispanic } & \multicolumn{3}{|c|}{ Non-Hispanic white } & \multicolumn{3}{|c|}{ Non-Hispanic black } \\
\hline & Total & Male & Female & Total & Male & Female & Total & Male & Female & Total & Male & Female \\
\hline$\ldots \ldots \ldots$ & 77.3 & 74.5 & 80.2 & 78.8 & 75.3 & 82.4 & 77.6 & 75.0 & 80.2 & 71.8 & 68.0 & 75.7 \\
\hline $1 \ldots \ldots \ldots \ldots$ & 76.7 & 73.9 & 79.6 & 78.2 & 74.7 & 81.8 & 76.9 & 74.3 & 79.5 & 71.6 & 67.8 & 75.4 \\
\hline $5 \ldots \ldots \ldots \ldots$ & 72.8 & 70.0 & 75.6 & 74.2 & 70.8 & 77.8 & 73.0 & 70.4 & 75.6 & 67.7 & 63.9 & 71.5 \\
\hline $10 \ldots \ldots \ldots \ldots$ & 67.8 & 65.0 & 70.7 & 69.3 & 65.8 & 72.8 & 68.0 & 65.5 & 70.6 & 62.8 & 59.0 & 66.6 \\
\hline$\ldots \ldots \ldots$ & 62.9 & 60.1 & 65.7 & 64.3 & 60.9 & 67.9 & 63.0 & 60.5 & 65.6 & 57.9 & 54.1 & 61.7 \\
\hline $20 \ldots \ldots \ldots \ldots$ & 58.0 & 55.3 & 60.8 & 59.5 & 56.1 & 63.0 & 58.2 & 55.7 & 60.7 & 53.2 & 49.6 & 56.8 \\
\hline $25 \ldots \ldots \ldots \ldots$ & 53.3 & 50.8 & 56.0 & 54.7 & 51.5 & 58.1 & 53.4 & 51.1 & 55.9 & 48.8 & 45.3 & 52.1 \\
\hline $30 \ldots \ldots \ldots \ldots$ & 48.7 & 46.2 & 51.2 & 50.1 & 46.9 & 53.3 & 48.8 & 46.5 & 51.1 & 44.3 & 41.0 & 47.4 \\
\hline $35 \ldots \ldots \ldots \ldots$ & 44.1 & 41.8 & 46.5 & 45.4 & 42.4 & 48.5 & 44.2 & 42.1 & 46.4 & 39.9 & 36.8 & 42.8 \\
\hline $40 \ldots \ldots \ldots \ldots$ & 39.6 & 37.4 & 41.8 & 40.8 & 37.9 & 43.7 & 39.7 & 37.6 & 41.7 & 35.6 & 32.6 & 38.3 \\
\hline $45 \ldots \ldots \ldots \ldots$ & 35.1 & 33.0 & 37.2 & 36.2 & 33.5 & 39.0 & 35.2 & 33.3 & 37.1 & 31.3 & 28.6 & 33.9 \\
\hline $50 \ldots \ldots \ldots \ldots$ & 30.7 & 28.7 & 32.7 & 31.8 & 29.2 & 34.4 & 30.8 & 29.0 & 32.6 & 27.3 & 24.6 & 29.6 \\
\hline $55 \ldots \ldots \ldots \ldots$ & 26.5 & 24.7 & 28.3 & 27.6 & 25.1 & 29.9 & 26.6 & 24.9 & 28.2 & 23.4 & 21.0 & 25.6 \\
\hline $60 \ldots \ldots \ldots \ldots$ & 22.6 & 20.9 & 24.1 & 23.6 & 21.3 & 25.7 & 22.6 & 21.1 & 24.0 & 19.8 & 17.6 & 21.7 \\
\hline $65 \ldots \ldots \ldots \ldots$ & 18.8 & 17.4 & 20.1 & 19.8 & 17.8 & 21.6 & 18.8 & 17.5 & 20.0 & 16.6 & 14.7 & 18.2 \\
\hline $70 \ldots \ldots \ldots \ldots$ & 15.3 & 14.1 & 16.3 & 16.4 & 14.7 & 17.8 & 15.2 & 14.1 & 16.1 & 13.7 & 12.1 & 15.0 \\
\hline $75 \ldots \ldots \ldots \ldots$ & 12.0 & 11.1 & 12.8 & 13.2 & 11.8 & 14.2 & 11.8 & 10.9 & 12.5 & 11.1 & 9.8 & 11.9 \\
\hline $80 \ldots \ldots \ldots \ldots$ & 9.1 & 8.4 & 9.6 & 10.4 & 9.3 & 11.1 & 8.8 & 8.2 & 9.3 & 8.7 & 7.8 & 9.3 \\
\hline $85 \ldots \ldots \ldots \ldots$ & 6.7 & 6.2 & 7.0 & 8.1 & 7.3 & 8.6 & 6.4 & 5.9 & 6.6 & 6.7 & 6.1 & 7.0 \\
\hline
\end{tabular}

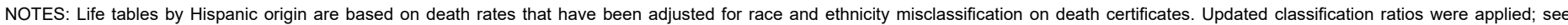
Technical Notes. Estimates are based on provisional data for 2020. Provisional data are subject to change as additional data are received.

SOURCE: National Center for Health Statistics, National Vital Statistics System, Mortality, 2020.

was 77.3 years, declining by 1.5 years from 78.8 in 2019 (8). Life expectancy at birth for males was 74.5 years in 2020 , representing a decline of 1.8 years from 76.3 years in 2019. For females, life expectancy declined to 80.2 years, decreasing 1.2 years from 81.4 years in 2019 (Figure 1).

Figure 1. Life expectancy at birth, by sex: United States, 2000-2020

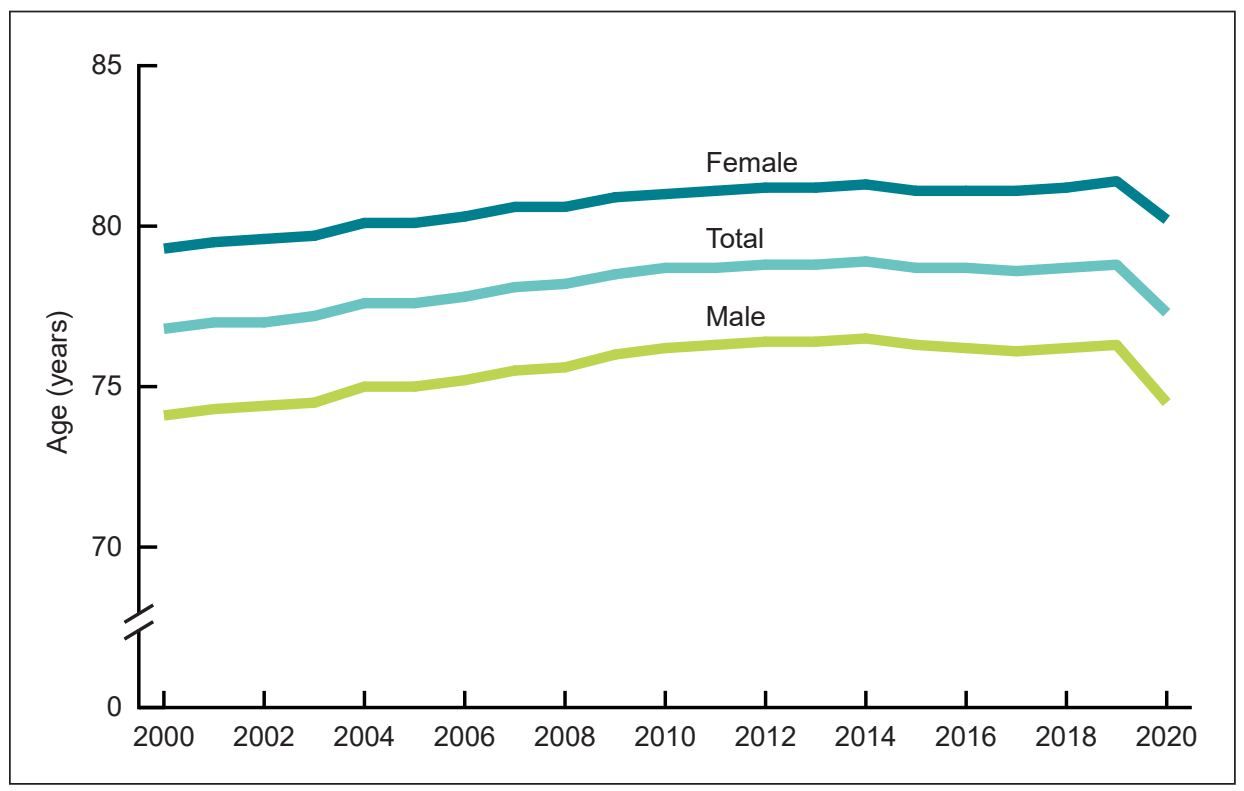

NOTES: Life expectancies for 2019 by Hispanic origin and race are not final estimates; see Technical Notes. Estimates are based on provisional data for 2020. Provisional data are subject to change as additional data are received.

SOURCE: National Center for Health Statistics, National Vital Statistics System, Mortality data.

\section{Life expectancy by Hispanic origin and race}

Between 2019 and 2020, life expectancy decreased by 3.0 years for the Hispanic population (81.8 to 78.8 ) (Figure 2). It decreased by 2.9 years for the non-Hispanic black population (74.7 to 71.8 ) and by 1.2 years for the nonHispanic white population (78.8 to 77.6). In 2020, the Hispanic population had a life expectancy advantage of 1.2 years over the non-Hispanic white population, declining from an advantage of 3.0 years in 2019 (Figure 3). The Hispanic advantage relative to the non-Hispanic black population decreased from 7.1 to 7.0 years between 2019 and 2020. The non-Hispanic white life expectancy advantage relative to the non-Hispanic black population increased from 4.1 to 5.8 years between 2019 and 2020 .

Among the six Hispanic origin -racesex groups (Figure 4), the decrease in life expectancy between 2019 and 2020 was greatest for Hispanic males, whose life expectancy declined by 3.7 years $(79.0$ to 75.3), followed by non-Hispanic black males with a decline of 3.3 years $(71.3$ to 68.0), non-Hispanic black females with a decline of 2.4 years (78.1 to 75.7 ), 
Figure 2. Life expectancy at birth, by Hispanic origin and race: United States, 2019 and 2020

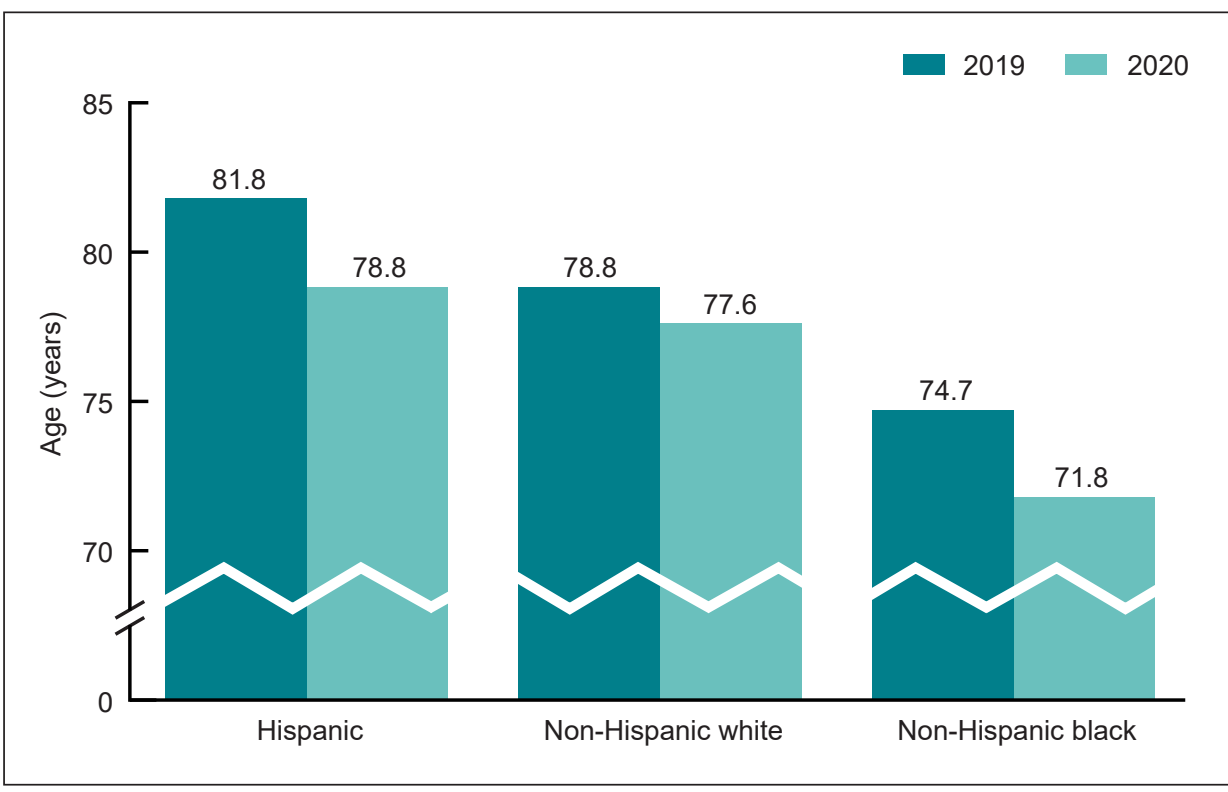

NOTES: Life expectancies for 2019 by Hispanic origin and race are not final estimates; see Technical Notes. Estimates are based on provisional data for 2020 . Provisional data are subject to change as additional data are received.

SOURCE: National Center for Health Statistics, National Vital Statistics System, Mortality data.
Hispanic females with a decline of 2.0 years (84.4 to 82.4), non-Hispanic white males with a decline of 1.3 years $(76.3$ to 75.0), and non-Hispanic white females with a decline of 1.1 years (81.3 to 80.2$)$.

\section{Effect on life expectancy of changes in cause-specific mortality}

Increases or decreases in life expectancy represent the sum of positive and negative contributions of causespecific death rates. Declines in causespecific mortality contribute to increases in life expectancy while increases in cause-specific mortality contribute to decreases in life expectancy. If the negative contributions (i.e., increases in cause-specific death rates) are greater than the positive contributions (i.e., decreases in cause-specific deaths rates) then the result is a decline in life expectancy. If negative and positive contributions offset each other, then the result would be no change in life expectancy (see Technical Notes for a description of the partitioning method).

The decline of 1.5 years in life expectancy between 2019 and 2020 was primarily due to increases in mortality due to COVID-19 (73.8\% of the negative
Certain conditions originating in the perinatal period $(4.0 \%)$.

For the male population, the 1.8 year decline in life expectancy was mostly due to increases in mortality due to COVID-19 (68.7\%), unintentional injuries $(14.0 \%)$, homicide $(4.4 \%)$, diabetes $(2.4 \%)$, and Chronic liver disease and cirrhosis $(2.3 \%)$. The decline in life expectancy was offset by decreases in mortality due to cancer (51.7\%), CLRD (17.5\%), Influenza and pneumonia (5.3\%), Alzheimer disease (4.7\%), and suicide (4.6\%).

For females, the decline in life expectancy of 1.2 years was primarily due to increases in mortality due to COVID-19 (79.8\%), unintentional injuries (6.8\%), diabetes $(2.7 \%)$, Chronic liver disease and cirrhosis $(2.3 \%)$, and homicide $(1.0 \%)$. These effects were offset by decreases in mortality due to cancer (34.7\%), CLRD (21.2\%), heart disease $(16.3 \%)$, suicide $(4.1 \%)$, and stroke $(3.7 \%)$.

The Hispanic population experienced the largest decline in life expectancy between 2019 and 2020 (3.0 years). This decrease was primarily due to increases in mortality due to COVID-19 (90.0\%), unintentional injuries $(4.2 \%)$, diabetes
Figure 3. Differences between groups in life expectancy at birth: United States, 2019 and 2020

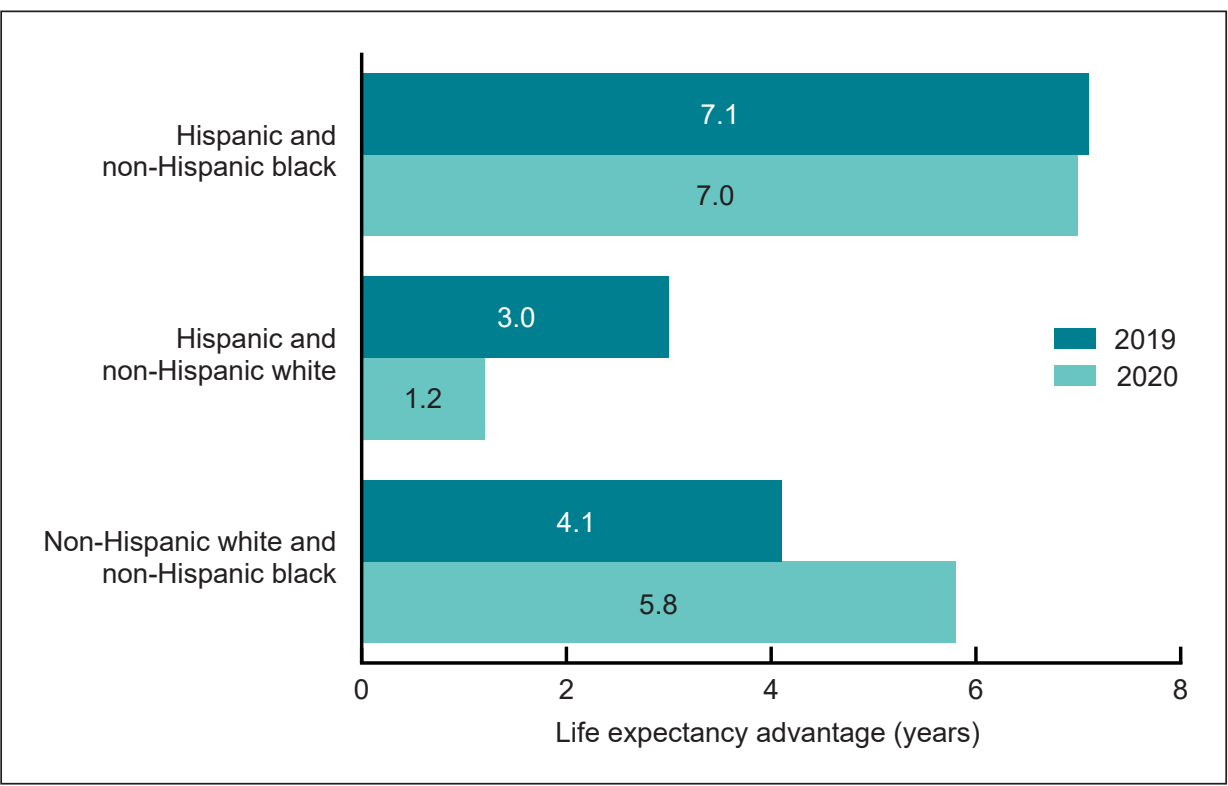

NOTES: Life expectancies for 2019 by Hispanic origin and race are not final estimates; see Technical Notes. Estimates are based on provisional data for 2020. Provisional data are subject to change as additional data are received.

SOURCE: National Center for Health Statistics, National Vital Statistics System, Mortality data. 
Figure 4. Change in life expectancy at birth, by Hispanic origin and race and sex: United States, 2019-2020

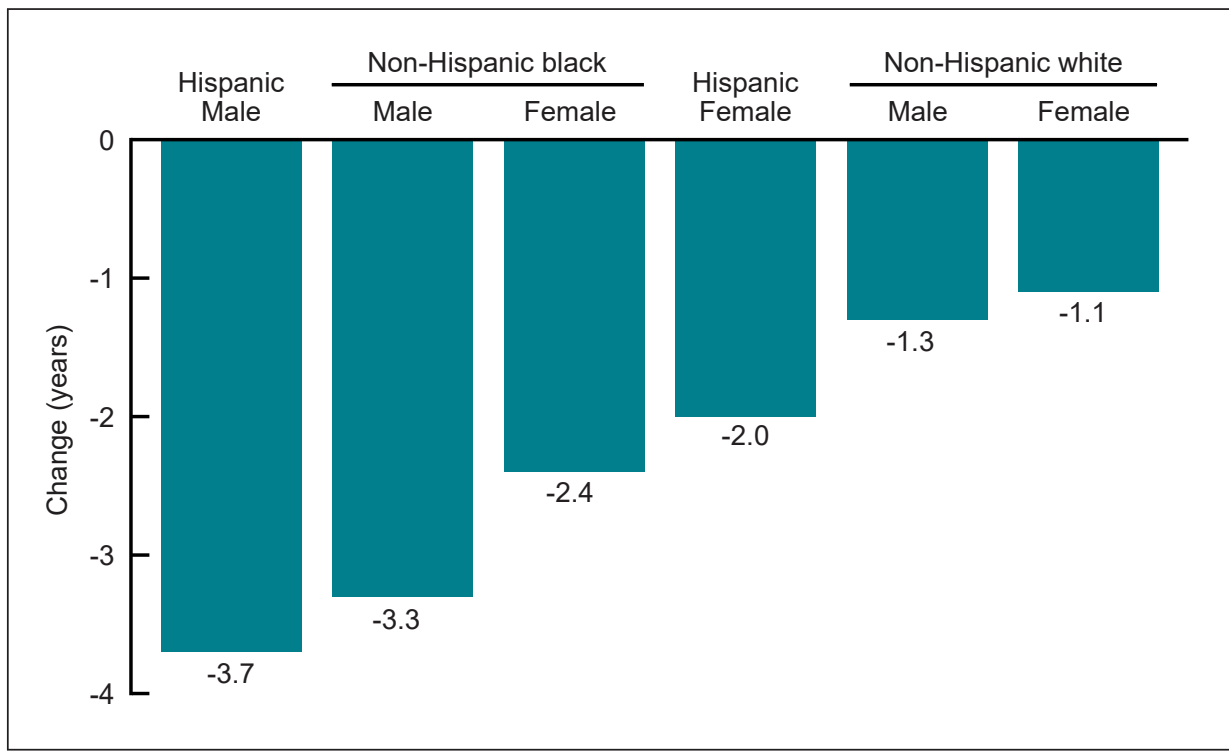

NOTES: Life expectancies for 2019 by Hispanic origin and race are not final estimates; see Technical Notes. Estimates are based on provisional data for 2020. Provisional data are subject to change as additional data are received.

SOURCE: National Center for Health Statistics, National Vital Statistics System, Mortality data.

(1.8\%), homicide (1.0\%), and Chronic liver disease and cirrhosis $(0.9 \%)$ (Figure 6). The decline in life expectancy would have been greater were it not for the offsetting effects of decreases in mortality due to cancer (38.2\%), heart disease (14.1\%), stroke (9.7\%), CLRD (9.1\%), and Alzheimer disease (8.4\%).

The second greatest decline in life expectancy was experienced by the non-Hispanic black population (2.9 years). The decline was due primarily to increases in mortality due to COVID-19 (59.3\%), unintentional injuries $(11.9 \%)$, homicide $(7.7 \%)$, heart disease $(5.9 \%)$, and diabetes $(3.6 \%)$. The decrease in life expectancy was offset by decreases in mortality due to cancer $(68.0 \%)$; Certain conditions originating in the perinatal period (11.3\%); Congenital malformations, deformations and chromosomal abnormalities (4.4\%); Aortic aneurysm and dissection (2.5\%); and Pneumonitis due to solids and liquids $(2.2 \%)$.

The non-Hispanic white population experienced the smallest decline in life expectancy (1.2 years), primarily due to increases in mortality due to COVID-19 (67.9\%), unintentional injuries (14.2\%), Chronic liver disease and cirrhosis $(3.3 \%)$, diabetes $(2.2 \%)$, and homicide
$(1.2 \%)$. The negative effects of these causes were offset by decreases in mortality due to cancer (40.1\%), CLRD (28.2\%), suicide (11.8\%), kidney disease (4.4\%), and Pneumonitis due to solids and liquids $(2.8 \%)$.

\section{Discussion and Conclusions}

U.S. life expectancy at birth for 2020, based on nearly final data, was 77.3 years, the lowest it has been since 2003. Male life expectancy (74.5) also declined to a level not seen since 2003 , while female life expectancy (80.2) returned to the lowest level since 2005 . The Hispanic population experienced the largest decline in life expectancy between 2019 and 2020, from 81.8 to 78.8 years, reaching a level lower than what it was in 2006 (80.3 years), the first year for which life expectancy estimates by Hispanic origin were produced (9). The non-Hispanic black population experienced the second largest decline in life expectancy (from 74.7 to 71.8 ) and was the lowest estimate seen since 2000 for the black population (regardless of Hispanic origin). Life expectancy for the non-Hispanic white population declined from 78.8 to 77.6 years, a level last observed in 2002 for the white population (regardless of Hispanic origin).

Racial and ethnic mortality disparities in life expectancy increased in 2020. For example, the non-Hispanic white life expectancy advantage over the nonHispanic black population increased by 41.5\% between 2019 (4.1) and 2020 (5.8). Life expectancy for the black population has consistently been lower than that of the white population, but the gap had been narrowing during the past three decades, from 7.1 years in 1993 to 4.1 years in 2019 (10). The last time the gap in life expectancy between the white and black populations was this large was in 1999 (10).

Conversely, the gap between the Hispanic and non-Hispanic white populations decreased by $60 \%$ between 2019 (3.0) and 2020 (1.2). The Hispanic population lost more than one-half of the mortality advantage it had experienced relative to the nonHispanic white population. Rather than a positive outcome, the narrowing of the life expectancy gap between the two populations is a stark indicator of worsening health and mortality outcomes for a population that paradoxically has been, prior to the COVID-19 pandemic, able to defy expectations consistent with its disadvantaged socioeconomic profile $(2,9,11)$.

Mortality due to COVID-19 had, by far, the single greatest effect on the decline in life expectancy at birth between 2019 and 2020, overall, among men and women, and for the three race and Hispanic-origin groups shown in this report. Among the causes contributing negatively to the change in life expectancy, COVID-19 contributed $90 \%$ for the Hispanic population, $67.9 \%$ for the non-Hispanic white population, and $59.3 \%$ for the non-Hispanic black population. Among the other causes of death that negatively contributed to the change in life expectancy, unintentional injuries, homicide, and diabetes affected all three Hispanic origin and race groups. For all three populations, unintentional injuries had the greatest 
Figure 5. Contribution of leading causes of death to the change in life expectancy, by sex and total population: United States, 2019-2020

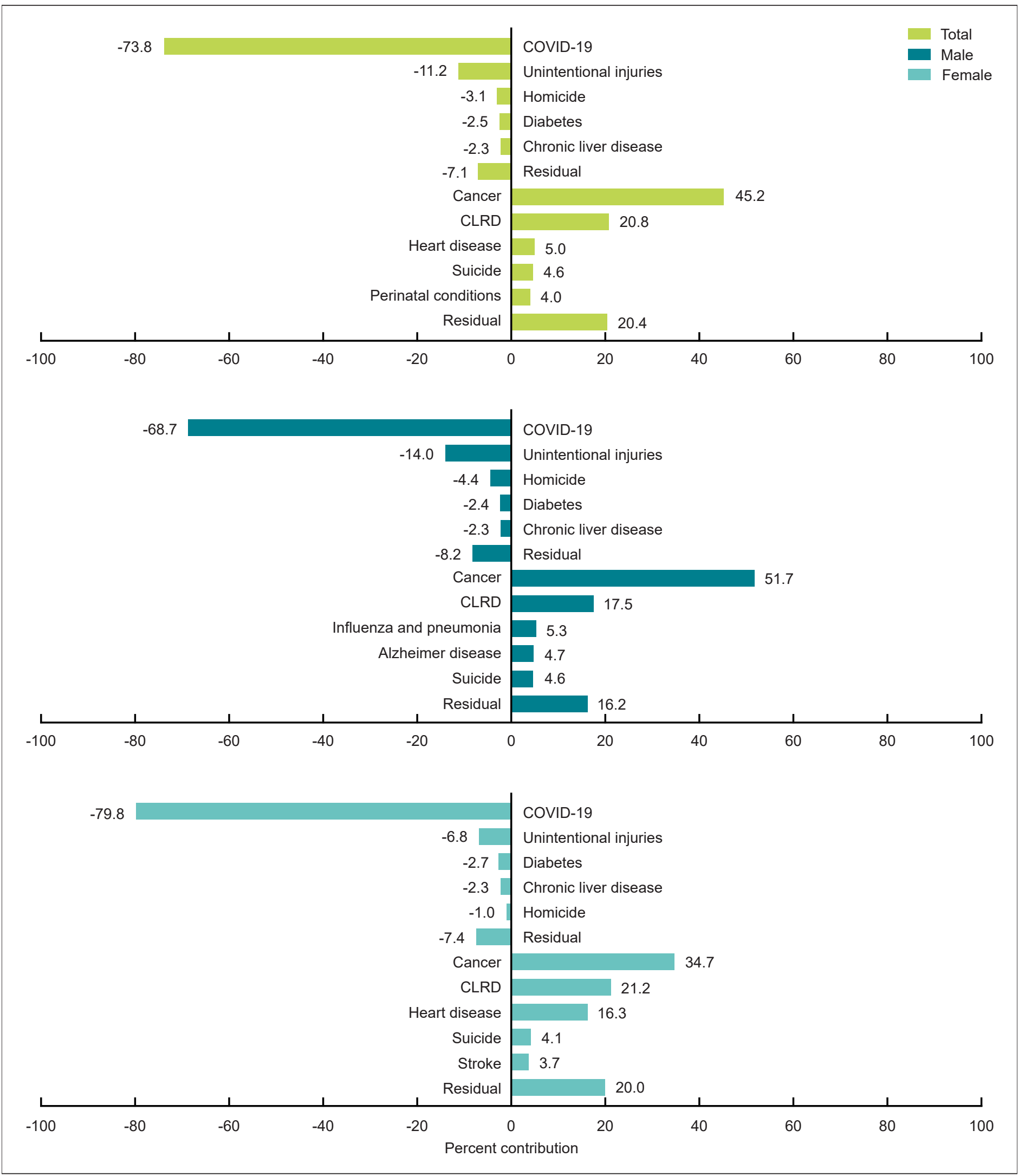

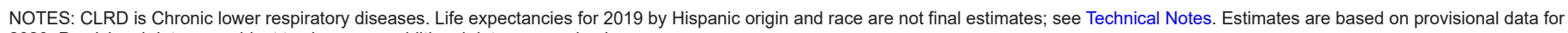
2020. Provisional data are subject to change as additional data are received.

SOURCE: National Center for Health Statistics, National Vital Statistics System, Mortality data. 
Figure 6. Contribution of leading causes of death to the change in life expectancy, by Hispanic origin and race: United States, 2019-2020

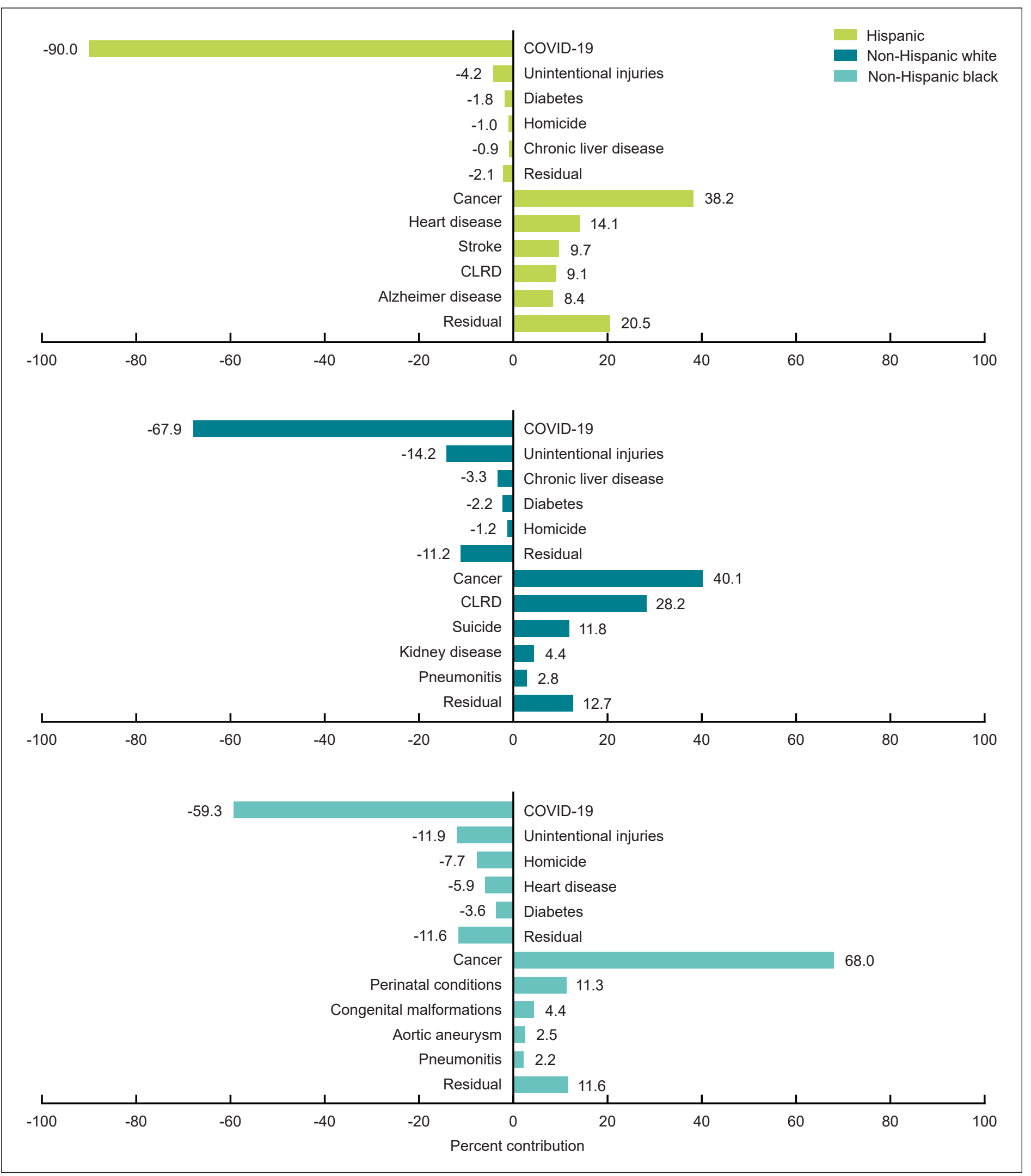

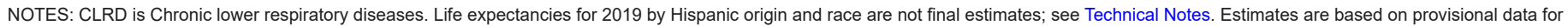
2020. Provisional data are subject to change as additional data are received.

SOURCE: National Center for Health Statistics, National Vital Statistics System, Mortality data. 
effect out of these three causes $(14.2 \%$, $11.9 \%$, and $4.2 \%$ for the non-Hispanic white, non-Hispanic black, and Hispanic populations, respectively). Increases in unintentional injury deaths in 2020 were largely driven by drug overdose deaths (12).

The life expectancy estimates presented in this report differ in important ways from those based on data for the first half of 2020 (January through June) (1). Life expectancy for the Hispanic population declined an additional 1.1 years from 79.9 years for the first half of 2020 to 78.8 years for the full-year 2020. Life expectancy declined a further 0.4 year for the nonHispanic white population (78.0 to 77.6) and 0.2 year for the non-Hispanic black population (72.0 to 71.8). As a result, the Hispanic and non-Hispanic black populations switched places. Between 2019 and the first half of 2020, the nonHispanic black population experienced a decline in life expectancy of 2.7 years, followed by the Hispanic population (1.9 years), and the non-Hispanic white population (0.8 year). Between 2019 and 2020 (full year), the Hispanic population experienced a decline in life expectancy of 3.0 years, followed by the non-Hispanic black (2.9 years), and nonHispanic white (1.2 years) populations. A likely explanation for these changes may be group differences in the monthly distributions of COVID-19 deaths throughout the year. Indeed, a review of the monthly distribution of COVID-19 deaths revealed notable differences between the three populations. For the non-Hispanic black population, the percentages of COVID-19 deaths were similar across the two halves of the year $(49.5 \%$ and $50.3 \%)$. In contrast, for the Hispanic population, $67.6 \%$ of all COVID-19 deaths occurred during the second half of the year. Similarly, for the non-Hispanic white population $70.5 \%$ of COVID-19 deaths occurred during the second half of the year.

The provisional mortality data on which the life tables are based have several limitations. First, the timeliness of death certificate data varies by jurisdiction and time. Some jurisdictions have historically taken longer to submit death certificates because paper records were submitted rather than electronic records, staffing shortages, or other localized issues. More recently, jurisdictions were differently affected by the pandemic. Many jurisdictions increased their frequency of death certificate submissions, while some faced staffing challenges, data processing disruptions, or other issues. Some jurisdictions expanded their use of electronic death registration systems in 2020, which may have affected the timeliness of data submission. The effect of recent changes in timeliness will not be apparent until data are finalized. Another limitation is the variation in timeliness due to age and cause of death. Certain age groups, particularly under 5 years, may be underrepresented (5). Deaths requiring investigation, including infant deaths, deaths due to external injuries, and drug overdose deaths take longer to complete and may be underreported in the 3 to 6 months after the death occurred. Lastly, the timeliness of death certificate data by race or ethnicity has not been studied. Differences in timeliness by these factors may result in underestimation of deaths for specific groups. The underestimation of infant deaths, for example, will have a disproportionate effect on life expectancy at birth given the latter's sensitivity to infant mortality, which is generally higher than mortality at all other ages up to the mid-50s or so.

\section{References}

1. Arias E, Tejada-Vera B, Ahmad F. Provisional life expectancy estimates for January through June, 2020. Vital Statistics Rapid Release; no 10. Hyattsville, MD: National Center for Health Statistics. 2021. Available from: https://www.cdc.gov/nchs/ data/vsrr/VSRR010-508.pdf.

2. Arias E, Heron M, Hakes JK. The validity of race and Hispanic-origin reporting on death certificates in the United States: An update. National Center for Health Statistics. Vital Health Stat 2(172). 2016. Available from: https://www.cdc.gov/nchs/ data/series/sr_02/sr02_172.pdf.

3. Arias E, Xu JQ. United States life tables, 2018. National Vital Statistics Reports; vol 69, no 12. Hyattsville, MD: National Center for Health Statistics. 2020. Available from: https://www.cdc.gov/nchs/data/nvsr/ nvsr69/nvsr69-12-508.pdf.

4. Ahmad FB, Bastian B. Quarterly provisional estimates for selected indicators of mortality, 2018Quarter 1, 2020. National Center for Health Statistics. National Vital Statistics System, Vital Statistics Rapid Release Program. 2020. Available from: https://www.cdc. gov/nchs/nvss/vsrr/mortality.htm.

5. Ahmad FB, Dokpesi P, Escobedo L, Rossen L. Timeliness of death certificate data by sex, age, and geography. Vital Statistics Rapid Release; no 9. Hyattsville, MD: National Center for Health Statistics. June 2020. Available from: https:// www.cdc.gov/nchs/data/vsrr/ vsrr009-508.pdf.

6. Rossen LM, Ahmad FB, Spencer MR, Warner M, Sutton P. Methods to adjust provisional counts of drug overdose deaths for underreporting. Vital Statistics Rapid Release; no 6. Hyattsville, MD: National Center for Health Statistics. August 2018. Available from: https://www.cdc. gov/nchs/data/vsrr/report006.pdf.

7. Rossen LM, Womack LS, Spencer MR, Ahmad FB. Timeliness of infant death data for infant mortality surveillance and quarterly provisional estimates. Vital Statistics Rapid Release; no 5. Hyattsville, MD: National Center for Health Statistics. 2018. Available from: https://www.cdc.gov/nchs/data/vsrr/ report005.pdf.

8. Kochanek K, Xu JQ, Arias E. Mortality in the United States, 2019. Data Brief, no 395. Hyattsville, MD: National Center for Health Statistics. 2020. Available from: https://www. cdc.gov/nchs/products/databriefs/ db395.htm. 
9. Arias E. United States life tables by Hispanic origin. National Center for Health Statistics. Vital Health Stat 2(152). 2010. Available from: https:// www.cdc.gov/nchs/data/series/sr_02/ sr02_152.pdf.

10. Arias E, Xu JQ. United States life tables, 2017. National Vital Statistics Reports; vol 68, no 7. Hyattsville, MD: National Center for Health Statistics. 2019. Available from: https://www.cdc.gov/nchs/data/nvsr/ nvsr68/nvsr68_07-508.pdf.

11. Markides KS, Coreil J. The health of Hispanics in the southwestern United States: An epidemiologic paradox. Public Health Rep 101(3):253-65.

12. Ahmad FB, Anderson RN. The leading causes of death in the US for 2020. JAMA. 325(18):1829-30. 2021. DOI:10.1001/jama.2021.5469.

13. Chiang CL. The life table and its applications. Malabar, FL: R.E. Krieger Publishing Company. 1984.

14. Silcocks PBS, Jenner DA, Reza R. Life expectancy as a summary of mortality in a population: Statistical considerations and suitability for use by health authorities. J Epidemiol Community Health 55:38-43. 2001.

15. Kochanek KD, Maurer JD, Rosenberg HM. Causes of death contributing to changes in life expectancy: United States, 1984-89. National Center for Health Statistics. Vital Health Stat 20(23). 1994.

Available from: https://www.cdc. gov/nchs/data/series/sr_20/sr20_023. pdf.

16. Arriaga EE. Changing trends in mortality decline during the last decades. In: Ruzicka L, Wunsch G, Kane P, editors. Differential mortality: Methodological issues and biosocial factors. Oxford, England: Clarendon Press. 1989.

17. Arriaga EE. Measuring and explaining the change in life expectancies. Demography 21(1): 83-96. 1984.
18. Murphy SL, Xu JQ, Kochanek KD, Arias E, Tejada-Vera B. Deaths: Final data for 2018. National Vital Statistics Reports; vol 69, no 13. National Center for Health Statistics. 2020. Available from: https://www. cdc.gov/nchs/data/nvsr/nvsr69/ nvsr69-13-508.pdf. 


\section{Technical Notes}

The methodology used to estimate the provisional 2020 life tables (Internet tables I-1 through I-12), on which the life expectancy estimates presented in this report are based, differs from what is used to estimate the annual U.S. national life tables in several ways (3). First, the life tables presented in this report are based on provisional death counts rather than on final death counts. Second, they are based on monthly population estimates rather than on annual mid-year population estimates. Third, they are abridged period life tables closed at ages 85 and over rather than complete period life tables closed at ages 100 and over. The main reason for the differences in methodology is data availability. Final death counts for the year 2020 will be not be available until late in 2021. Similarly, census mid-year population estimates for 2020 are not yet available. The tables are closed at ages 85 and over because Medicare data, used to supplement vital statistics data at older ages, are not yet available. Another difference is the use of provisional birth counts rather than final birth counts and linked birth and infant death data used for life tables by Hispanic origin and race as these data are not yet available. Finally, abridged rather than complete life tables are used to address the effects of small death counts for some Hispanic origin-racesex-age groups (Internet tables I-1 through I-12).

Standard errors of the two most important functions, the probability of dying and life expectancy (Internet tables I-3 through I-4), are estimated under the assumption that the data are only affected by random error because over $99 \%$ of deaths that occurred during the first half of 2020 are included. However, the possibility that certain jurisdictions and age groups may be underrepresented for later months could potentially lead to biases not accounted for by the estimated standard errors. Other possible errors, including age, and Hispanic origin and race misreporting on death certificates are also not considered in the calculation of the variances or standard errors of the life table functions.
The methodology used to estimate the 2019 complete period life tables, from which the 2019 life expectancy estimates in this report are generated, is the same as that used every year to estimate the annual U.S. life tables, with a minor modification (3). The standard 2019 birth and mortality data files were used rather than the 2019 linked birth/infant death data file for the life tables by Hispanic origin and race, because the linked data for 2019 are not yet available. The final 2019 life tables by Hispanic origin and race will be updated once the linked birth and infant death data become available (Internet table I-15).

\section{Data for calculating life table functions}

\section{Vital statistics data}

Mortality data used to estimate the life tables presented in this report include over $99 \%$ of the deaths that occurred in 2020, although certain jurisdictions and age groups may be underrepresented for later months. Death data are typically over $99 \%$ complete 3 months after the date of death, but this can vary by jurisdiction, age of the decedent, and the cause of death. Most jurisdictions submit over $90 \%$ of death data by 3 months after the date of death, but some jurisdictions may take longer to submit death records. Death data for decedents aged under 5 years are $90 \%$ complete 3 months after the date of death, and $95 \%$ complete 6 months after the death occurred. Provisional estimates of infant mortality are typically presented with a 9-month lag as infant deaths require additional investigation and take longer to complete. Timeliness also varies by cause of death; with deaths due to external causes taking additional time to investigate and complete death certificates. Provisional estimates for most external causes of death (e.g., falls, suicides, unintentional injuries) are presented with a 6-month lag, while drug overdose deaths are presented with a 9-month lag.

Beginning with the 2018 data year, all 50 states and D.C. reported deaths based on the 2003 revision of the U.S. Standard Certificate of Death for the entire year (3). The revision is based on the 1997 Office of Management and Budget (OMB) standards (3). The 1997 standards allow individuals to report more than one race and increased the race choices from four to five by separating the Asian and Pacific Islander groups. The Hispanic category did not change, remaining consistent with previous reports.

The Hispanic origin and race groups in this report follow the 1997 standards and differ from the race categories used in reports for data years prior to 2018 . From 2003 through 2017, not all deaths were reported using the 2003 certificate revision that allowed the reporting of more than one race based on the 1997 OMB race standards (3). During those years, multiple-race data were bridged to the 1977 standard single-race categories. Use of the bridged-race process was discontinued for the reporting of mortality statistics in 2018 when all states collected data on race according to 1997 OMB guidelines for the full data year.

\section{Census population data}

The population data used to estimate the life tables shown in this report are July 1, 2020, monthly postcensal population estimates based on the 2010 decennial census and are available from the U.S. Census website at https://www. census.gov/data/tables/time-series/demo/ popest/2010s-national-detail.html.

\section{Preliminary adjustment of the data}

\section{Adjustments for unknown age}

An adjustment is made to account for the small proportion of deaths for which age is not reported on the death certificate. The number of deaths in each age category is adjusted proportionally to account for those with not-stated age. The following factor $(F)$ is used to make the adjustment. $F$ is calculated for the total and for each sex group within a racial and ethnic population for which life tables are constructed: 


$$
F=D / D^{a}
$$

where $D$ is the total number of deaths and $D^{a}$ is the total number of deaths for which age is stated. $F$ is then applied by multiplying it by the number of deaths in each age group.

\section{Adjustment for misclassification of Hispanic origin and race on death certificates}

The latest research to evaluate Hispanic origin and race reporting on U.S. death certificates found that the misclassification of Hispanic origin and race on death certificates in the United States accounts for a net underestimate of $3 \%$ for total Hispanic deaths, a net underestimate of less than one-half percent for total non-Hispanic black deaths, and no under or overestimate for total non-Hispanic white deaths or for the population racially classified as white or black, irrespective of Hispanic origin (10). These results are based on a comparison of self-reported Hispanic origin and race on Current Population Surveys (CPS) with Hispanic origin and race reported on the death certificates of a sample of decedents in the National Longitudinal Mortality Study (NLMS) who died during the period 1999-2011 (10).

NLMS-linked records are used to estimate sex-age-specific ratios of CPS Hispanic origin and race counts to death certificate counts (2). The CPS to death certificate ratio, or "classification ratio," is the ratio of the weighted count of self-reported race and ethnicity on the CPS to the weighted count of the same racial or ethnic category on the death certificates of the sample of NLMS decedents described above. It can be interpreted as the net difference in assignment of a specific Hispanic origin and race category between the two classification systems and can be used as a correction factor for Hispanic origin and race misclassification (10).

The assumption is made that the race and ethnicity reported by a CPS respondent is more reliable than proxy reporting of race and ethnicity by a funeral director who has little personal knowledge of the decedent. Further, public policy embodied in the 1997 OMB standard mandates that self-identification should be the standard used for the collection and recording of race and ethnicity information (10).

The NLMS-based classification ratios discussed above are used to adjust the age-specific number of deaths for ages 1-85 years and over for the total, Hispanic, non-Hispanic white, and nonHispanic black populations, and by sex for each group, as follows:

$$
{ }_{n} D_{x}={ }_{n} D_{x}^{F} \bullet{ }_{n} C R_{x}
$$

where ${ }_{n} D_{x}^{F}$ is the age-specific number of deaths adjusted for unknown age as described above, ${ }_{n} C R_{x}$ are the sex- and age-specific classification ratios used to correct for the misclassification of Hispanic origin and race on death certificates, and ${ }_{n} D_{x}$ are the final age-specific counts of death adjusted for age and Hispanic origin and race misclassification.

Because NLMS classification ratios for infant deaths are unreliable due to small sample sizes, corrections for racial and ethnic misclassification of infant deaths are addressed by using infant death counts and live birth counts from the linked birth and infant death data files rather than the traditional birth and death data files (3). In the linked file, each infant death record is linked to its corresponding birth record so that the race and ethnicity of the mother reported on the birth record can be ascribed to the infant death record. Due to the unavailability of birth and infant death data at this time, the traditional birth and death data files are used instead for both the 2019 and 2020 life tables. Typically, infant mortality rates based on these data are overestimated by approximately $4 \%$ for the Hispanic population and 3\% for the non-Hispanic black population and underestimated by $2 \%$ for the nonHispanic white population (1).

\section{Calculation of abridged life tables}

The abridged life tables were constructed using the methodology developed by Chiang with minor modifications described below (13). The life table columns include:

\section{Age}

The age interval between two exact ages, $x$ and $x+n$. The abridged life tables contain 19 age groups (in years): $0-1$, $1-5,5-10,10-15, \ldots, 80-85$, and 85 and over.

\section{Probability of dying, ${ }_{n} q_{x}$}

The first step in the calculation of an abridged period life table is the estimation of the age-specific probability of dying, ${ }_{n} q_{x}$. The probability of dying between two exact ages, $x$ and $x+n$, is defined as:

$$
{ }_{n} q_{x}=\frac{n_{x} \bullet{ }_{n} M_{x}}{1+\left(1-a_{x}\right) \bullet n_{x} \bullet{ }_{n} M_{x}}
$$

where ${ }_{n} M_{x}$ is the age-specific period death rate, $\frac{{ }_{n} D_{x}}{{ }_{n} P_{x}}$, and ${ }_{n} D_{x}$ is the agespecific provisional death count, ${ }_{n} P_{x}$ is the July 1, 2020, age-specific monthly population estimates based on the 2010 decennial population census population count; $n_{x}$ is the size in years of the age interval; and $a_{x}$ is the fraction of life lived by those who died in the age interval.

\section{Number surviving, $l_{x}$}

The number of persons surviving to the beginning of the age interval from the original 100,000 hypothetical live births is defined as:

$$
l_{x+n}=l_{x}-{ }_{n} d_{x}
$$

where the radix of the table $l_{0}=100,000$.

\section{Number dying, ${ }_{n} d_{x}$}

The number of persons dying in the hypothetical life table cohort in the age interval $x$ and $x+n$ is defined as:

$$
{ }_{n} d_{x}=l_{x} \bullet{ }_{n} q_{x}
$$




\section{Person-years lived, ${ }_{n} L_{x}$}

The number of person-years lived by the hypothetical life table cohort within an age interval $x$ and $x+n$ is defined as:

$$
{ }_{n} L_{x}=n_{x} \bullet\left(l_{x}-{ }_{n} d_{x}\right)+a_{x} \bullet n_{x} \bullet{ }_{n} d_{x}
$$

where ${ }_{\infty} L_{x}$, the person-years lived in the final open-ended age interval, is defined as:

$$
{ }_{\infty} L_{x}=\frac{l_{x}}{{ }_{\infty} M_{x}}
$$

\section{Total number of person-years lived, $T_{x}$}

The number of person-years that would be lived by the hypothetical life table cohort after the beginning of the age interval $x$ and $x+n$ is defined as:

$$
T_{x}=\sum_{x=0}^{x=x+\infty}{ }_{n} L_{x}
$$

\section{Expectation of life, $e_{x}$}

The average number of years to be lived by those in the hypothetical life table cohort surviving to age $x$ is defined as:

$$
e_{x}=\frac{T_{x}}{l_{x}}
$$

\section{Variances and standard errors of the probability of dying and life expectancy}

Variances are estimated under the assumption that the mortality data on which the life tables are based are not affected by sampling error and are subject only to random variation. However, although over $99 \%$ of deaths that occurred from January through December, 2020 are included, the data may be biased by the possibility that certain jurisdictions and age groups may be underrepresented for later months. These errors as well as those resulting from age and Hispanic origin and race misreporting on death certificates are not considered in the calculation of the variances or standard errors of the life table functions.

The methods used to estimate the variances of ${ }_{n} q_{x}$ and $e_{x}$ are based on Chiang (13) with a minor modification in the estimate of the variance of $e_{x}$ in the closing age of the life table (14). Based on the assumption that deaths are binomially distributed, Chiang proposed the following equation for the variance of ${ }_{n} q_{x}$ :

$$
\operatorname{Var}\left({ }_{n} q_{x}\right)=\frac{{ }_{n}^{2} q_{x}^{2}\left(1-{ }_{n} q_{x}\right)}{{ }_{n} D_{x}}
$$

where ${ }_{n} D_{x}$ is the age-specific number of deaths.

$$
\operatorname{Var}\left(e_{x}\right)=\frac{\sum_{x=0}^{x=75-84} l_{x}^{2} \bullet\left[\left(1-a_{x}\right) \bullet n_{x}+e_{(x+n)}\right]^{2} \bullet \operatorname{Var}\left({ }_{n} q_{x}\right)}{l_{x}^{2}}
$$

and for ages 85 and over:

$$
\operatorname{Var}\left(e_{85+}\right)=\frac{l_{85+}^{2}}{M_{85+}^{4}} \bullet \operatorname{Var}\left(M_{85+}\right)
$$

\section{Causes of death contributing to changes in life expectancy}

To measure changes in mortality, a discrete method, developed by Arriaga (15-17), was used to estimate the contribution of mortality change by causes of death based on changes in life expectancy, which is described as a procedure that "estimates the number of years added to or removed from life expectation because of the decrease or increase (respectively) of the central mortality rates of life tables" (16). With this method one can partition the change in life expectancy over time or between two separate groups of populations. In this report, Arriaga's technique is used to partition by cause-of-death changes in life expectancy at birth in the United States from 2019 to 2020.

The method partitions changes into component additive parts and identifies the causes of death having the greatest influence, positive or negative, on changes in life expectancy based on rankable causes of death (15-17). This is the same method as that used by NCHS annually to analyze changes in life expectancy (18).

\section{Acknowledgments}

The authors are grateful for the content review provided by Sherry L. Murphy, Mortality Statistics Branch (MSB). The authors thank Amy Branum, Office of the Director; Robert N. Anderson, MSB; and Andrés Berruti, Division of Vital Statistics for their reviews and comments. NCHS Office of Information Services, Information Design and Publishing staff edited and produced this report: editor Nora Castro; typesetters and graphic designers Michael Jones (contractor) and Kyung Park. 


\section{Suggested citation}

Arias E, Tejada-Vera B, Ahmad F, Kochanek KD. Provisional life expectancy estimates for 2020. Vital Statistics Rapid Release; no 15. Hyattsville, MD: National Center for Health Statistics. July 2021. DOI:

https://dx.doi.org/10.15620/cdc:107201.

\section{Copyright information}

All material appearing in this report is in the public domain and may be reproduced or copied without permission; citation as to source, however, is appreciated.

\section{National Center for Health Statistics}

Brian C. Moyer, Ph.D., Director

Amy M. Branum, Ph.D., Associate

Director for Science

\section{Division of Vital Statistics}

Steven Schwartz, Ph.D., Director

Andrés A. Berruti, Ph.D., M.A., Acting

Associate Director for Science 